\title{
The relevance of outcrossing for the dynamic management of genetic resources in predominantly selfing Triticum aestivum L. (bread wheat)
}

\author{
Jérome Enjalbert $^{\text {a* }}$, Isabelle Goldringer ${ }^{\mathrm{a}}$, \\ Jacques David $^{\mathrm{b}}$, Philippe Brabant ${ }^{\mathrm{a}, \mathrm{c}}$ \\ a Station de génétique végétale, Institut national de recherche agronomique, \\ Inapg, Ups, Ferme du Moulon, 91190 Gif-sur-Yvette, France \\ b Station de génétique et amélioration des plantes, Institut national de recherche \\ agronomique, Domaine de Melgueil, 34130 Mauguio, France \\ c Institut national agronomique Paris-Grignon, 16, rue Claude Bernard, \\ 75005 Paris, France
}

\begin{abstract}
The mating system is of major concern for the dynamic management of genetic resources. We investigated the outcrossing rate of six experimental wheat populations, derived from two genetic pools (PA and PB) which have been cultivated at four French sites. The replicates of the two segregating populations have undergone 10 years of multiplication in isolation, with no artificial selection. For each population, 78 individuals were randomly sampled and genotyped for 25 codominant loci revealed by 15 restriction fragment length polymorphism (RFLP) probes. Outcrossing rates were estimated on the basis of the multilocus heterozygote deficiency. Estimates ranged from 2.4 to $10.1 \%$, depending on the population. The outcrossing rate appeared to be affected by the cultivation site, and also by the interaction between the genetic pool and the cultivation site. No significant pool effect was found over sites. The use of natural or modified outcrossing rates is suggested for the management of gene flows between the subpopulations of a metapopulation. Consequences of recombination events within and between populations are discussed in the context of short-term adaptive response of populations and long-term elimination of weakly deleterious mutations. (C) Inra/Elsevier, Paris
\end{abstract}

outcrossing rate / gene flow / dynamic management / genetic resources / Triticum aestivum $\mathrm{L}$.

Résumé - Taux naturels d'allofécondation dans des populations expérimentales de blé, et conséquences pour une gestion dynamique des ressources génétiques. Le régime de reproduction est un paramètre essentiel pour le pilotage d'un programme de gestion dynamique des ressources génétiques. Cet article s'attache à l'estimation

\footnotetext{
* Correspondence and reprints
} 
du taux d'allogamie dans six populations expérimentales de blé tendre, issues de deux pools génétiques différents (PA et $\mathrm{PB}$ ) cultivés dans quatre sites distincts. Chaque population a subi dix années de multiplication en isolement, sans sélection consciente. Dans chacune d'elles, 78 individus ont été aléatoirement échantillonnés et génotypés pour vingt-cinq locus codominants, grâce à quinze sondes RFLP. Les taux d'allogamie ont été estimés à partir de l'hétérozygotie résiduelle multilocus. Un niveau d'allogamie élevé pour cette espèce cléistogame a été observé. Les estimations varient de 2,4 à $10,1 \%$ suivant les populations. Ces taux d'allofécondation dépendent d'une part du site de culture, et d'autre part d'une interaction entre composition génétique initiale et site de culture. L'intérêt de l'allogamie tant pour la génération de nouvelles combinaisons génétiques que pour la purge des mutations faiblement délétères est discuté. L'utilisation des taux naturels d'allogamie pour instaurer des flux de gènes entre les populations est proposée dans l'optique d'une gestion en métapopulation. (C) Inra/Elsevier, Paris

taux d'allogamie / flux de gènes / gestion dynamique / ressources génétiques / Triticum aestivum $\mathbf{L}$.

\section{INTRODUCTION}

During the past 30 years, national and international efforts have led to the construction of large collections of genetic resources. For the major cereal crops (rice, corn, wheat), these collections mainly comprise sampled seeds, stored in cold rooms of central gene banks (Frankel et al., 1995). Though gene banks are a safe and efficient way to preserve genetic resources from extinction, the long-term conservation of resources in isolation from the environment leads to a decrease in their usefulness. Whereas genetic resources are protected in cold rooms, pathogens are evolving and the climate may change. Resources are no longer exposed to selective pressures, and eventually will prove ill-adapted to a new environment (Simmonds, 1962; Henry et al., 1991). Hence, complementary strategies, qualified as 'in situ or ex situ dynamic managements' (DM) are presently developed to circumvent this evolutionary freeze. Their aim is to maintain or mimic natural processes responsible for the diversification and conservation of genetic diversity.

On the basis of the metapopulation concept (Levins, 1970; Olivieri et al., 1990), a pilot programme of dynamic management of genetic resources of bread wheat (Triticum aestivum L.) started in France in 1984. Its general rules are to let genetically heterogeneous populations evolve in different environments and to manage gene flows between populations. This ex situ management develops the concept of 'mass reservoir' described by Simmonds (1962). In a first 10-year period, no gene flows were realised in order to allow the study of differentiation and local adaptation with no interference from migration.

After a few generations of cultivation in a French multilocal network, the populations showed significant differentiation for agromorphological and biochemical traits. These genetic changes are mostly due to the three following selective pressures:

i) environmental factors, such as climate, which has induced a north-south gradient of flowering time in both PA and PB pools (David et al., 1992); 
ii) between-plant competition, which led to the undesirable elimination of dwarfing genes (rht1 and $r h t 2)$ segregating in the initial populations (Pontis, 1992);

iii) pathogens, as shown by the differentiation of populations for their composition in resistance genes to powdery mildew (Le Boulc'h, 1994; Le Boulc'h et al., 1994).

Besides these selection pressures, the mating system is of great importance for the adaptive response of each population, as it plays a major role in the structuring of within- and between-population diversity, when gene flows are set up between populations.

On a within-population scale, a high level of selfing allows the rapid fixation of the best genotypes and thus a short-term adaptation, whereas outcrossing maintains genetic diversity and the potential for future adaptation, by producing new recombinant genotypes (Allard, 1979). David et al. (1993) showed that, in a finite population under selection, the optimal adaptive response (accumulation of positive alleles) is obtained with an intermediate outcrossing rate, whose value depends on the size and fitness of the population.

Outcrossing, recombination and natural selection are also critical for purging populations of low effective sizes $(<1000)$ from the genetic load. Recent studies of natural populations and mutation accumulation experiments have shown that slightly deleterious mutations (inducing a loss of total fitness of 1 to $5 \%$ ) occur at a rate equivalent to $0.5-1$ new mutation per diploid genome and per generation (Mukaï et al., 1972; Lopez and Lopez-Fanjul, 1993; Keightley, 1996). Such empirical data combined with theoretical considerations (Charlesworth et al., 1993) shed new light on what should be the long-term goals of dynamic management of genetic diversity. Mutational load is expected to build up rapidly in a purely selfing population of a few hundred individuals and should lead such a population to extinction due to the reduced fertility/viability of individuals (phenomenon commonly known as Muller's ratchet [Muller, 1964]). In this context, a mixed mating system is optimal because it allows both efficient purging of the genome and recombination (David et al., 1993; Ronfort and Couvet, 1995).

On a metapopulation scale, while selection over the metapopulation contributes to the conservation of genetic diversity by the fixation of different combinations of adaptive alleles in each site, it also increases the genetic drift, leading to the random loss of alleles with a slightly positive effect on fitness. Genetic drift also leads to the differential fixation of weakly deleterious alleles randomly appearing through mutation in the different subpopulations. The occurrence of interpopulation recombination enables the reintroduction of lost positive alleles, and to a lesser degree, incorporation of new positive alleles appearing through mutation in other populations. Knowledge of natural outcrossing rate is thus essential to optimise the management of gene flows between populations and could facilitate its practical realisation.

It is therefore strategic to study the breeding system of the populations cultivated in the wheat dynamic management network. Triticum aestivum L. is usually considered as a selfing species because of its cleistogamous flowers. However, outcrossing has been reported, like for other self-fertilising species of the Triticeae genus (2-3 \% for T. aestivum L. in Hayes, 1918 and Martin, 1990; 1-3\% for T. turgidum L. in Tsegaye, 1996). 
This paper gives estimates of outcrossing rates of six genetically heterogeneous wheat populations of the DM programme submitted to natural selection for 10 years. We used molecular markers to derive outcrossing rates from the estimated fixation parameters $f$ (Wright's statistics). As these populations originate from two segregating populations (PA and $\mathrm{PB}$ ) cultivated at three different sites, our second aim was to detect if original genetic composition and cultivation sites influence the outcrossing rate of populations. Lastly, we discuss the consequences of outcrossing rates for the adaptive response of the wheat populations and consider the use of these natural crossing events for the setting of gene flows between populations.

\section{MATERIALS AND METHODS}

\subsection{History of populations}

Two segregating populations (PA and $\mathrm{PB}$ ) were created each by a manual pyramidal cross of two distinct sets of 16 inbred lines (for PA, see Thomas et al., 1991). In 1984, after 3 years of bulk multiplication, the populations were split between, respectively, seven and eight sites of a French multilocal network (either Inra stations or agricultural and agronomic high schools) to settle local subpopulations. The demographic size of each founding population was about 10000 individuals. At each site, 10000 to 15000 plants have been grown each year in isolated plots, separately harvested and sampled to generate the next population. As previously mentioned, wheat is usually cleistogamous, with a relatively low pollen/ovule ratio (2 000 to 4000 ; Cruden, 1977). When outcrossing occurs, flowers are wind-pollinated.

\subsection{Plant material}

Six populations were studied after 10 years of multiplication at the same site: three PA populations cultivated in Le Moulon $\left(48^{\circ} 9^{\prime} \mathrm{N} 2^{\circ} \mathrm{E}\right)$, Rennes $\left(48^{\circ}\right.$ $\left.1^{\prime} \mathrm{N} 2^{\circ} \mathrm{W}\right)$ and Toulouse $\left(43^{\circ} 6^{\prime} \mathrm{N} 1^{\circ} \mathrm{E}\right)$, and three PB populations cultivated in Le Moulon, Rennes and Venours $\left(45^{\circ} 8^{\prime} \mathrm{N} 1^{\circ} \mathrm{W}\right)$. From the bulk harvest of the 1994 season, 78 individuals were randomly sampled and analysed. Adding the 3 years of multiplication prior to the initial distribution of seeds over the network to the 10-year multiplication period, these populations resulted from 13 cycles of natural mating after the last manual crosses. To estimate the initial frequencies of markers in the founding populations, two random samples of inbred lines derived by single seed descent (SSD) from the initial populations PA0 and PB0 were also studied.

\subsection{Molecular study}

Because of the low level of polymorphism at the protein level (Gale and Sharp, 1988), we used restriction fragment length polymorphism (RFLP) markers, which are codominant and expected to show sufficient polymorphism to reveal heterozygosity. 
Total deoxyribonucleic acid (DNA) was extracted from lyophilised young leaves following a rapid procedure adapted from Dellaporta et al. (1983). Enzyme restriction, electrophoresis, blotting onto Hybond $\mathrm{N}^{+}$membranes (Amersham) and nonradioactive hybridisation (DIG ${ }^{\circledR}$ Boehringer-Mannheim) were performed as described by Lu et al. (1994).

P. Leroy provided us with 35 genomic DNA probes, obtained and mapped by Inra-Génoblé of Clermont-Ferrand, France (Nelson et al., 1995a,b). These probes were chosen for their high polymorphism information content (Nelson et al., 1995a,b) estimated over 14 lines. K. Devos provided us with five additional probes obtained and mapped by the John Innes Centre, Norwich, UK (Gale et al., 1997).

The RFLP diversity of this set of probes was screened on the 32 genitors of the PA and PB pools, and the 12 most polymorphic enzyme/probe combinations were retained: EcoRI with fba69, fba381 and fbb09; HindIII with fba65, fba127, fba152, fba242 and fbb12; Dra I with fba204 and fba251 for the InraGénoblé probes; EcoRI with PSR 144 and PSR 622 for the John Innes Centre. Information on the probes can be obtained from the GrainGenes database (http://wheat.pw.usda.gov; French mirror site: http://grain.jouy.inra.fr).

As some probes exhibited polymorphism for nonmapped bands, the relations of allelism between new segregating bands were tested over the two PAO and PBO SSD and the DM populations.

\subsection{Genetic analysis}

To estimate the outcrossing rates, we chose measurement of mean heterozygosity for two main reasons. First, after 13 seasons of natural mating we expected the neutral markers to be very close to the inbreeding equilibrium, so that we could use the relationship between $t$ and $f$. Second, whereas progeny analysis (Ritland and Jain, 1981) allows unambiguous detection of outcrossing events, the estimated outcrossing rate is only relevant for one breeding season. Moreover, we needed, for other purposes not developed herein, accurate estimates of allelic frequencies more easily achieved in predominantly selfer plants by random sampling than by progeny analysis.

Outcrossing rates of the populations were estimated from the observed level of heterozygosity deficiency $f$ of the sampled genotypes. In a population of infinite size without over- or underdominant selection, with a constant outcrossing rate $t$, the heterozygosity reaches an equilibrium value after a few generations (from one generation for complete outcrossing to ten generations for a $99 \%$ selfing population). As the census size of populations is large (>10 000) and because of the 13 years of free pollination, we assumed that $f$ was close to the equilibrium value.

With these assumptions, the estimation of outcrossing rate is given by

$$
\widehat{t}=\frac{1-\widehat{f}}{1+\widehat{f}}
$$

(Nei and Syakudo, 1958), where $\widehat{f}$ is the estimated inbreeding coefficient:

$$
\widehat{f}=1-\frac{H o}{H e}
$$


$\mathrm{Ho}$ is the observed proportion of heterozygotes in the sample,

$$
H e=1-\sum_{i=1}^{n} \widehat{p}_{i}^{2}
$$

the gene diversity as defined by Nei $(1958), n$, the number of alleles for a given locus and $\widehat{p}_{i}$ the estimated frequency of the allele $i$.

$f$ was estimated by the maximum likelihood method proposed by $\mathrm{Li}$ and Horovitz (1953) and Curie-Cohen (1982) for monolocus data. Assuming that there is no gametic disequilibrium, multilocus $\widehat{f}$ is the root of

$$
\frac{\sum_{l=1}^{L} N_{H e t}^{l}}{1-f}-\sum_{l=1}^{L} \sum_{i=1}^{N} n_{i i}^{l} \frac{1-\widetilde{p}_{i}^{l}}{\widetilde{p}_{i}^{l}-\left(1-\widetilde{p}_{i}^{l}\right) f}=0
$$

(Rousset and Raymond, 1995), where $N_{H e t}^{l}$ is the number of heterozygotes at locus $l, n_{i i}$ the number of homozygotes for allele $i$ at locus $l$ and $\widetilde{p}_{i}^{l}$ the frequency for allele $i$ at the locus $l$ observed in the sample.

Estimate $\hat{f}$ was numerically computed after estimation of the allelic frequencies, and used to calculate the $\widehat{t}$ value. A bootstrap resampling procedure over individuals was performed to determine the confidence interval of $\hat{t}$ (Weir, 1990). For each population, 500 bootstrap samples were used to calculate a distribution of values $(b=1, \ldots, 500)$.

To test the significance of differences in outcrossing rates $\left(t_{i}<t_{j}\right)$ between populations $i$ and $j$, pairwise subtraction between bootstrapped values of each population, $\widehat{t}_{j, b}-\widehat{t}_{t, b}$ allowed us to perform a one-tailed test (Efron and Tibshirani, 1982). The percentage of negative differences provided the probability associated with the test $H o: t_{i}=t_{j}$ against $H 1: t_{i}<t_{j}$.

To test the effects of the genetic composition (PA versus $\mathrm{PB}$ ) and of the site (Le Moulon versus Rennes), the bootstrap distributions of the following contrasts were calculated:

$$
\begin{aligned}
\delta \text { site }_{b} & =\left(\widehat{t}_{\text {PARennes }, b}+\widehat{t}_{\text {PBRennes }, b}\right)-\left(\widehat{t}_{\text {PAMoulon }, b}+\widehat{t}_{\text {PBMoulon }, b}\right) \\
\delta \text { pool }_{b} & =\left(\widehat{t}_{\text {PAMoulon }, b}+\widehat{t}_{\text {PARennes }, b}\right)-\left(\widehat{t}_{\text {PBMoulon }, b}+\widehat{t}_{\text {PBRennes }, b}\right)
\end{aligned}
$$

\section{RESULTS}

\subsection{Polymorphism of RFLP markers}

Most of the RFLP genomic probes used for this study revealed multiband profiles, due to the hexaploid constitution of wheat. Over the 12 assayed probes, 23 codominant loci were examined, some probe/enzyme combinations showing up to five polymorphic loci. Thus, a single hybridisation led to a mean of 1.9 data points per individual. For many probes, new segregating bands were 
revealed in comparison with the mapping populations (Nelson et al., 1995a,b). Consequently, the mapping of these 23 loci on the genetic maps was not always possible. The Mendelian inheritance of the new polymorphic bands was verified using the segregation data of the SSD populations extracted from the initial populations in which a high level of fixation (96\%) allowed unambiguous determination of allelism relationships (results not shown). Over the 23 loci, the mean allelic diversity was 2.48 , ranging from two to five alleles per locus (table I). The mean gene diversity was $H e=0.35$, ranging from 0.09 to 0.59 .

Table I. Allelic diversity and Nei's gene diversity $H e$ of used RFLP markers.

\begin{tabular}{|c|c|c|c|c|}
\hline Probe & $\begin{array}{l}\text { Number of } \\
\text { locus }\end{array}$ & $\begin{array}{l}\text { Restriction } \\
\text { enzyme }\end{array}$ & $\begin{array}{c}\text { Allele } \\
\text { number }\end{array}$ & $\mathrm{He}$ \\
\hline$f b a 20^{*}$ & 1 & EcoRI & 5 & 0.59 \\
\hline fba65* & 2 & HindIII & $3 ; 2$ & $0.54 ; 0.24$ \\
\hline fba $69^{*}$ & 1 & EcoRI & 3 & 0.59 \\
\hline fba $127^{*}$ & 2 & HindIII & $2 ; 2$ & $0.20 ; 0.42$ \\
\hline fba152* & 3 & HindIII & $2 ; 2 ; 2$ & $0.45 ; 0.25 ; 0.32$ \\
\hline $\mathrm{fba}^{204^{*}}$ & 2 & Dra I & $3 ; 4 ; 2$ & $0.49 ; 0.55 ; 0.13$ \\
\hline fba242* & 3 & HindIII & $3 ; 2 ; 2$ & $0.54 ; 0.48 ; 0.10$ \\
\hline fba251* & 1 & Dra I & 3 & 0.52 \\
\hline$f b a 280^{*}$ & 2 & EcoRI & $2 ; 3$ & $0.46 ; 0.55$ \\
\hline fba381* & 1 & EcoRI & 3 & 0.42 \\
\hline$f b b 9^{*}$ & 1 & $E c o R I$ & 3 & 0.44 \\
\hline$f b b 12^{*}$ & 1 & HindIII & 3 & 0.51 \\
\hline$f b b 178^{*}$ & 2 & Dra I & $3 ; 2$ & $0.51 ; 0.09$ \\
\hline $\operatorname{PSR} 144^{* *}$ & 1 & Dra I & 2 & 0.49 \\
\hline PSR $622^{* *}$ & 1 & EcoRI & 3 & 0.55 \\
\hline
\end{tabular}

* Probe from Inra-Génoblé, Clermont-Ferrand, France (Nelson et al., 1995a,b); ** probe from Cambridge Laboratory, John Innes Centre (Devos and Gale, 1993).

\subsection{Outcrossing rates}

The heterozygosity observed after 13 generations was much higher than expected: 1 to $5 \%$ of mean heterozygosity was measured (data not shown), instead of $0.006 \%\left(\frac{1}{2^{13}}\right)$ expected for strict self-pollination. Values of single locus estimates of outcrossing rates ranged from 0 to $30 \%$, most of them being lower than $10 \%$ (figure 1). The highest outcrossing rates were observed for loci with a poor gene diversity, and thus a high standard error.

Analysis of variance (ANOVA) over the single-locus estimates (data not shown) did not reveal a significant RFLP effect: no locus exhibited consistently high or low levels of heterozygosity across the four populations. This indicated that no RFLP locus was in linkage disequilibrium with polymorphic genes controlling the outcrossing rate or submitted to overdominant selection in all populations. 

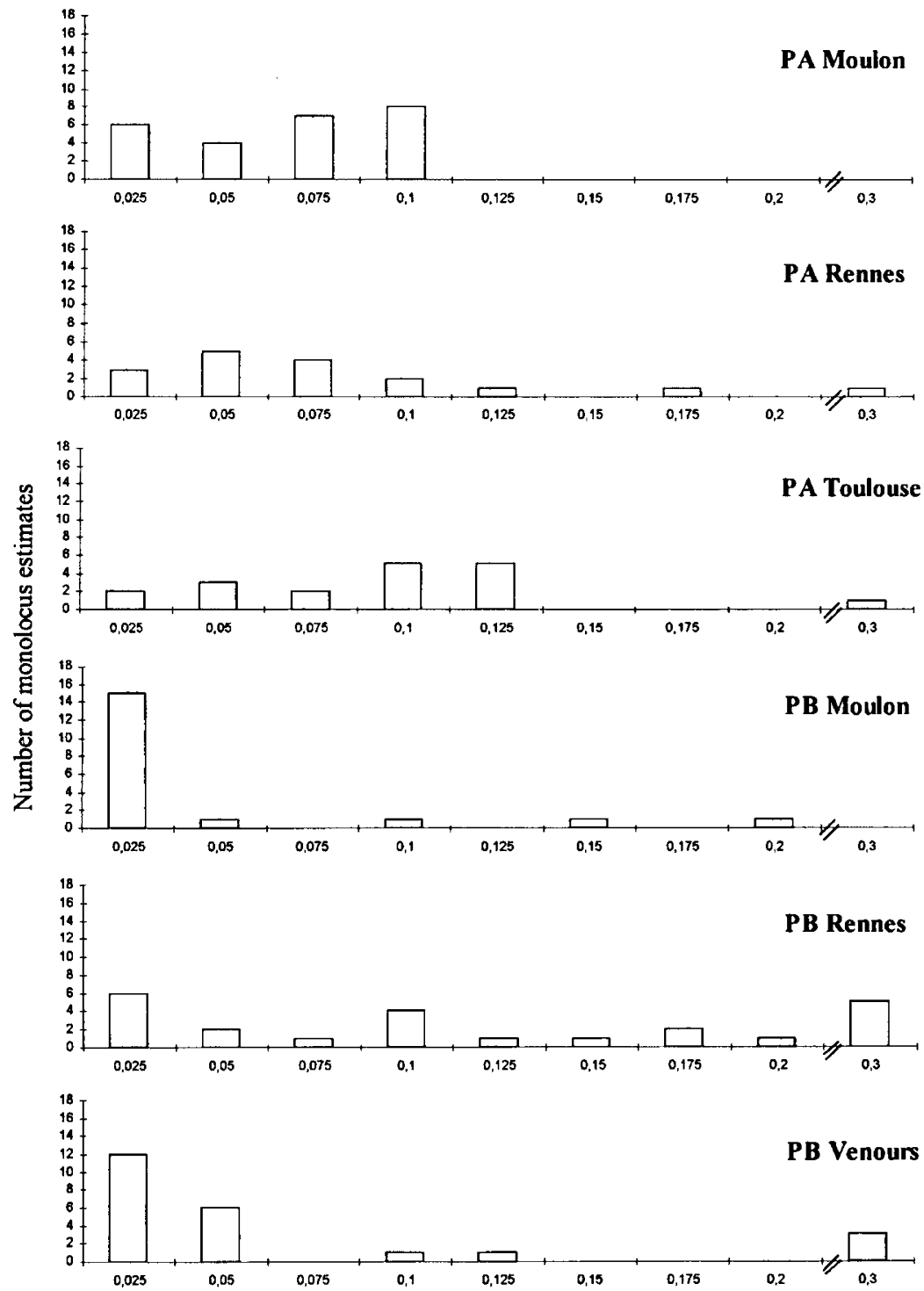

Outcrossing ratc

Figure 1. Distribution of the monolocus estimates of outcrossing rates for the six populations.

Multilocus estimates of outcrossing rates of the six populations ranged from 2.4 to $10.1 \%$ (table $I I$ ). This range is higher than the values reported by Martin (1990) for 12 commercial lines of bread wheat: 0.1 to $5.6 \%$ measured over 1 year, with a maximum mean over 3 years of $3.1 \%$.

The estimated outcrossing rates are roughly distributed in three groups of two populations: PB Moulon and PB Venours with the lowest outcrossing 
Table II. Estimates of the outcrossing rates, corresponding confidence intervals and bootstrap comparison.

\begin{tabular}{|c|c|c|c|c|c|c|c|}
\hline & & $\begin{array}{c}\text { PB } \\
\text { Moulon }\end{array}$ & $\begin{array}{c}\text { PB } \\
\text { Venours }\end{array}$ & $\begin{array}{c}\text { PA } \\
\text { Moulon }\end{array}$ & $\begin{array}{c}\text { PA } \\
\text { Rennes }\end{array}$ & $\begin{array}{c}\text { PB } \\
\text { Rennes }\end{array}$ & $\begin{array}{c}\text { PA } \\
\text { Toulouse }\end{array}$ \\
\hline & $\widehat{t}(\%)$ & $2.4 \%$ & $3.4 \%$ & $5.9 \%$ & $6.7 \%$ & $9.1 \%$ & $10.1 \%$ \\
\hline Interval $90 \% *$ & & $1.6-3.6$ & $2.0-5.6$ & $3.1-9.3$ & $4.2-9.9$ & $7.1-11.6$ & $7.1-13.7$ \\
\hline PB Moulon** & 2.4 & & & & & & \\
\hline PB Venours** & 3.4 & 0.21 & & & & & \\
\hline PA Moulon** & 5.9 & 0.030 & 0.140 & & & & \\
\hline PA Rennes** & 6.7 & 0.004 & 0.030 & 0.348 & & & \\
\hline PB Rennes** & 9.1 & $<0.002$ & $<0.002$ & 0.066 & 0.364 & & \\
\hline PA Toulouse** & 10.1 & $<0.002$ & $<0.002$ & 0.054 & 0.098 & 0.134 & \\
\hline
\end{tabular}

* Determined over 500 bootstrapped values of $\widehat{t}$; ${ }^{* *}$ probability associated with the test $H o:=\widehat{t}_{i}=\widehat{t}_{j}$ against $\widehat{t}_{i}<\widehat{t}_{j}$.

rates (around $3 \%$ ), PA Moulon and PA Rennes with intermediate values (near $6 \%$ ) and PB Rennes and PA Toulouse with the highest rates (around $10 \%$ ). According to comparison tests, PB Moulon differed significantly from all the others with the exception of PB Venours, a population which, in turn, differs significantly from all the others except PA Moulon, all other comparisons being not significant.

A significant site effect was found, with $\operatorname{Pr}[\delta$ site $<0]=0.004$, whereas no pool effect was detected $(\operatorname{Pr}[\delta$ pool $<0]=0.4)$. Nevertheless, site-pool interaction was present, as the PA and PB populations had inverse classifications in Rennes and Le Moulon.

\section{DISCUSSION}

Our results showed that the wheat populations of the DM network cultivated under natural conditions, though cleistogamous, can exhibit a relatively high outcrossing rate (ranging from 2.4 to $10.1 \%$ ). These estimations rely upon the assumption of selective neutrality and consequently could be biased upward due to the selective advantage of heterozygotes in populations in which strong competition takes place between individuals. In winter wheat, low heterosis $(\approx 10 \%)$ has been reported for yield surveyed on plots of homogeneous genetic composition (Oury et al., 1990), but we might expect heterosis for individual fitness in heterogeneous populations to be stronger, since hybrids are, on average, taller and bloom earlier than their inbred parents, both traits contributing to a better competitive aptitude. Even with $20 \%$ heterosis on fitness explained by a single-locus model, however, 13 cycles of complete selfing only raised the heterozygote frequency from 0.006 to $0.08 \%$ (data not shown), a value significantly lower than the rates observed in this study. This theoretical consideration, associated with the observation that no locus exhibited significant excess of heterozygotes across all studied populations, leads us to argue that the outcrossing rate of our populations is often as high as several percent, ranging from 2 to 10 . 
Such levels of outcrossing are commonly reported in other species classically described as selfing (table $I$ in Schoen and Brown, 1991). In the few highly selfing species (outcrossing rate $\leq 1 \%$ ), such as Arabidopis thaliana or some Avena species, outcrossing events might be due to accidents in the development of some anthers or to the exceptional infiltration of exogenous pollen and might have low evolutionary impact. On the other hand, outcrossing rate, even as low as $5 \%$, should be explained by different mechanisms.

\subsection{Origin and stability of outcrossing rates in dynamically managed populations}

In some grasses, environment has a strong effect on fertility and outcrossing propensity. Low luminosity and low temperature during meiosis have been shown to cause pollen sterility in rice ( $\mathrm{Li}$ et al., 1996) and winter wheat (Demotes-Mainard et al., 1995). Demotes-Mainard et al. (1995) showed that this sensitivity to low luminosity has a genetic basis, the two studied lines Pernel and Moulin exhibiting very contrasted responses to the stress. This physiological response should lead to strong year-to-year and site-to-site variation in the rate of outcrossing. Contrasted climatic conditions of the DM network are most likely to affect the amount of outcrossing realised in the populations, either through partial male sterilities or by shifting of male and female phenologies. Thus, one explanation for the high outcrossing rate of populations grown in Rennes could be the cloudy weather in spring and in the beginning of the summer in the west of France. On the other hand, Henry et al. (1991), by studying a locus coding for seed storage protein, have previously shown that populations grown in the south of France displayed significant excesses of heterozygotes as compared with populations grown in the north. This was explained by a protogynous flowering at high temperatures. Our results, in accord with this previous study, underline the importance of environmental factors for the mating system.

Although we did not detect an effect of the genetic background (PA or PB) on the outcrossing ability, the PA population of Le Moulon showed a significantly higher rate of outcrossing than PB Le Moulon, and the two PB populations of Le Moulon and Venours were the most selfing populations. A rather high level of outcrossing has also been observed in a recurrent selection programme based on the same genetic background as the PA populations. Spikes or spikelets have often been found with open flowers receptive to exogenous pollen, indicating that no viable pollen was available for a cleistogamous pollination, a phenomenon well known in wheat. This trend to partial male sterility may be due to the presence in the genitors of PA of the Courtot cultivar, a line known for its high degree of pollen sterility. Savy (1991) showed that within a population the individuals presented different rates of selfing, with the greatest proportion of plants being mainly selfing, with some individuals showing complete outbreeding. Thus, genetic and environmental factors probably interact to determine individual levels of outcrossing.

If site-to-site variation of outcrossing rates could be estimated, the yearto-year or plant-to-plant variations need to be evaluated because they will affect the efficiency of gene flow in schemes based on the population's mean outcrossing rate. 
However, which forces maintain the outcrossing ability of these populations? Simple theoretical models for the evolution of selfing predict that a selfing variant should spread due to its segregational advantage as soon as inbreeding depression (defined as one minus the relative fitness of selfed versus outcrossed progeny) does not exceed one half (Fisher, 1958). Other theoretical models (assuming population of finite size or spatial structuration) show that even with low heterosis for fitness, recombination is advantageous and maintains evolutionary stable rates of outcrossing at a few percent (David et al., 1993; Ronfort and Couvet, 1995). If the optimal multilocus genotype is not initially present in a population, the selection for favourable recombinant types slows down the counterselection of outcrossing abilities within the population. In the present study, the low heterosis of wheat combined with significant outcrossing rates led us to the conclusion either that a large part of the population must exhibit a few percent outcrossing, or that the heritability for high outcrossing rates must be low. Otherwise outcrossing plants should have been quickly eliminated and the outcrossing rates lower than reported here.

Beyond the exact nature of the selective forces acting on the mating system, outcrossing is expected to play a major role in the local adaptation of the populations of the DM network. By allowing occasional recombination events between individuals, such levels of outcrossing enable the production of better adapted genotypes (Allard, 1979) and simultaneously prevent rapid loss of favourable alleles trapped in inferior lines that would otherwise be wiped out of the population. Hence, comparing the level of diversity maintained on polygenic traits and the structure of genetic correlations between traits, a population with a mixed mating system involving a few percent outcrossing is qualitatively different from a pure selfing one.

\subsection{Consequences for managing the DM network}

The diversity of selective pressures present at the various sites of the network is a warrant for the maintenance of polymorphism on loci involved in adaptation (Henry et al., 1991). However, we argue that gene flows between populations are necessary to compensate for the variability lost within populations through drift and linkage drag due to selection. A rule of thumb could be the preservation of a certain level of within-population polymorphism for neutral traits, expecting that in case of change in selection gradients these previously neutral traits become adaptive. Several examples can be given to illustrate this possible feature. First, dramatic changes in environmental conditions can induce inversions in the hierarchy of the traits determining local fitness. Second, heterogeneous populations can experiment different successive phases of selection. When the adaptation for an important trait is finally realised by the exhaustion of the variability for that trait, natural selection will act more strongly on another trait which was of minor importance in the first stage of adaptation. In these cases of change in selective gradients, gene flows would allow local populations to enrich their variability for secondary traits, as they restart selection on primary traits when their variability has been exhausted by linkage drag or genetic drift. On the other hand, it is important not to impede local adaptation of populations to their site because of too high migration rates (Harrison and Hasting, 1996). By using the neutral theory of 
evolution as a guideline, the intensity of gene flow could be determined in order to limit the level of between-population differentiation on neutral genes, i.e. to ensure a minimum rate of migration $m$, so that $N e^{*} m=1$, where $N e$ is the local effective size of a population (Crow and Kimura, 1970). However, a higher migration could be necessary to preserve diversity of chromosomal segments in the neighbourhood of genes under strong selection.

To favour recombination between individuals, pollen migration should be favoured instead of seed migration. In outcrossing species both modes of migration are expected to produce similar effects (except for cytoplasmic genomes), but markedly different consequences are expected in the case of selfers. Seed migration could potentially split the recipient population into two compartments. If migrant genotypes are poorly adapted to local conditions, hybrid/outbreeding depression is expected and the efficiency of gene transfer via such schemes will be low. To circumvent such problems, Hauser et al. (1994) suggested to realise back crosses instead of first-generation hybrids to enhance genetic diversity in endangered populations. On the other hand, when some migrants display more competitive ability, they could potentially outcompete resident genotypes and eliminate the initial variability present in the population (especially if migrant and resident genotypes hardly recombine). Migration via pollen should avoid these phenomena by enforcing recombination of resident and migrant genotypes.

On the basis of the data obtained, natural outcrossing rates are sufficient to allow the incorporation of foreign migrants by the local population. To achieve a level of gene flow of one effective migrant per generation (neutralist guideline), two outcrossings per migrant pollen per population are required. Assuming a $5 \%$ rate of outcrossing in a population composed of 10000 plants, 500 individuals will potentially outcross. To ensure two crosses, migrant pollen should thus be provisioned as to represent $1 / 250$ of the total pollen pool. For wheat, this should be easily realised by surrounding populations with a belt of migrant plants.

Estimation of rates of natural outcrossing in populations combined with the knowledge of local effective sizes will make it possible to rationalise the management of the network. Such optimisation should be achieved by real experiments, analytical approaches and through modelling based on realistic parameters.

\section{ACKNOWLEDGEMENTS}

The authors are grateful to T. Bataillon and D. Schoen for scientific comments and for help in the translation of the paper, and they thank the anonymous reviewers for very helpful comments on the manuscript.

The wheat dynamic network was initiated by the 'Direction générale de l'enseignement et de la recherche' (DGER) of the French agriculture ministry and received scientific and financial support from the DGER, 'Institut national de la recherche agronomique' and 'Bureau des Ressources Génétiques' (BRG). This work is supported by a grant from the BRG. J. Enjalbert is the recipient of a doctoral fellowship from the French research and higher education ministry. 


\section{REFERENCES}

Allard R.W., The mating system and microevolution, Genetics 79 (1979) 115-126.

Charlesworth D., Morgan M.T., Charlesworth B., Mutation accumulation in finite outbreeding and inbreeding populations, Genet. Res. 61 (1993) 39-56.

Crow J.F., Kimura M., An Introduction to Population Genetics Theory, Harper International Edition, New York, 1970.

Cruden R.W., Pollen-ovule ratios: a conservative indicator of breeding systems in flowering plants, Evolution 31 (1977) 32-46.

Curie-Cohen M., Estimate of inbreeding in natural populations: a comparison of sampling properties, Genetics 100 (1982) 339-358.

David J.L., Savy J., Trottet M., Pichon M., Méthode de gestion dynamique de la variabilité génétique en milieu naturel. Exemple de populations composites de blé, in: Colloque international en hommage à Jean Pernès, 8-10 janvier 1992, Paris, France, 1992, pp. 337-350.

David J.L., Savy Y., Brabant P., Outcrossing and selfing evolution in populations under directional selection, Heredity 71 (1993) 642-651.

Dellaporta S., Wood J., Hicks J., A plant DNA minipreparation: version II, Plant Mol. Biol. Rep. 1 (1983) 19-21.

Demotes-Mainard S., Doussinault G., Meynard J.M., Effect of low radiation and low temperature at meiosis on pollen viability and grain set in wheat, Agronomie 15 (1995) 357-365.

Devos K., Gale M.D., The genetic maps of wheat and their potential in plant breeding, Outlook Agric. 22 (1993) 93-99.

Efron B., Tibshirani R.J., An Introduction to the Bootstraps, Chapman and Hall, New York, 1982.

Fisher R.A., The Genetical Theory of Natural Selection, Oliver and Boyd, London, 1958 .

Frankel O.H., Brown A.H.D., Burdon J.J., The Conservation of Plant Biodiversity, Cambridge University Press, Cambridge, 1995.

Gale M.D., Sharp P.J., Genetic markers in wheat-developments and prospects, in: Seventh International Wheat Genetic Symposium, Cambridge, 13-19 July 1988, Institute of Plant Science Research, 1988, pp. 469-473.

Gale M.D., Atkinson M.D., Chinoy C.N., Harcourt R.L., Jia J., Li Q.Y., Devos K.M., Genetic maps of hexaploid wheat, in: Eighth International Wheat Genetics Symposium, Beijing, China, 1997, pp. 29-40.

Harrison S., Hasting A., Genetic and evolutionary consequences of metapopulation structure, Tree 11 (1996) 180-183.

Hauser T.P., Damgaard C., Loeschcke V., Effects of Inbreeding in Small Plant Populations: Expectations and Implications for Conservation, Birkhaüser Verlag, Basel, 1994.

Hayes H.K., Natural crossing in wheat. A cause of impurities in breeding plotsbelief of some agronomists that hybrids frequently revert to the parental type, J. Hered. 9 (1918) 326-330.

Henry J.P., Pontis C., David J.L., Gouyon P.H., An experiment on dynamic conservation of genetic resources with metapopulations, in: Seitz A., Loeschcke V. (Eds.), Species Conservation: A Population-Biological Approach, Birkhaüser Verlag, Basel, 1991.

Keightley P.D., Nature of mutation load in Drosophila, Genetics 144 (1996) 19931999. 
Le Boulc'h V., Évolution de la résistance à l'oüdium (Erysiphe graminis) dans des populations de blé tendre (Triticum aestivum L.) menées en gestion dynamique, thèse, Institut national agronomique Paris-Grignon, Paris, 1994.

Le Boulc'h V., David J.L., Brabant P., Vallavieille-Pope C., Dynamic conservation of variability: response of wheat populations to different selective forces including powdery mildew, Genet. Sel. Evol. 26 (1994) 221-240.

Levins R., Extinction, in: Gerstenhaber M. (Ed.), Some Mathematical Questions in Biology, American Mathematical Society, Providence, RI, 1970, pp. 77-107.

Li C.C., Horovitz D., Some methods of estimating the inbreeding coefficient, Am. J. Hum. Genet. 5 (1953) 107-117.

Li H.B., Zhang Q., Liu A.M., Zou J.S., Chen Z.M., A genetic analysis of lowtemperature-sensitive sterility in indica-japonica rice hybrids, Plant Breeding 115 (1996) 305-309.

Lopez M.A., Lopez-Fanjul C., Spontaneous mutation for a quantitative trait in Drosophila melanogaster. II. Distribution of mutant effects on trait and fitness, Genet. Res. 61 (1993) 117-126.

Lu Y.H., Merlino M., Isaac P.G., Staccy J., Bernard M., Leroy P., A comparative analysis between $32 \mathrm{p}$ and digoxigenin-labelled single-copy probes for RFLP detection in wheat, Agronomie 14 (1994) 33-39.

Martin T.J., Outcrossing in twelve hard red winter wheat cultivars, Crop Sci. 30 (1990) 59-62.

Mukaï T., Chigusa S.I., Mettler L.E., Crow J.F., Mutation rate and dominance of genes affecting viability, Genetics 72 (1972) 335-355.

Muller H.J., The relation of recombination to mutational advance, Mutat. Res. 1 (1964) 2-9.

Nei M., Syakudo M., The estimation of outcrossing in natural populations, Jpn. J. Genet. 33 (1958) 46-51.

Nelson J.C., Sorrells M.E., Van Deynze A.E., Lu Y.H., Atkinson M., Bernard M., Leroy P., Faris J.D., Anderson J.A., Molecular mapping of wheat: major genes and rearrangements in homoeologous group 4, 5 and 6, Genetics 141 (1995a) 721-731.

Nelson J.C., Van Deynze A.E., Autrique E., Sorrells M.E., Lu Y.H., Negre S., Bernard M., Leroy P., Molecular mapping of wheat. Homoeologous group 3, Genome 38 (1995b) 525-533.

Olivieri I., Couvet D., Gouyon P.-H., The genetic of transient populations: research at the metapopulation level, Tree 5 (1990) 207-210.

Oury F.-X., Brabant P., Pluchard P., Bérard P., Rousset M., Étude multilocale de blés hybrides : niveaux d'hétérosis et élaboration du rendement, Agronomie 10 (1990) 735-748.

Pontis C., Utilisation de marqueurs génétiques pour le suivi de la variabilité de trois composites de blé tendre d'hiver ( T. aestivum L.) menées en gestion dynamique, thèse, Institut national agronomique Paris-Grignon, Paris, 1992.

Ritland K., Jain S., A model for the estimation of outcrossing rate and gene frequencies using $\mathrm{n}$ independent loci, Heredity 47 (1981) 35-52.

Ronfort J., Couvet D., A stochastic model of selection on selfing rates in structured populations, Genet. Res. 65 (1995) 209-222.

Rousset F., Raymond M., Testing heterozygote excess and deficiency, Genetics 140 (1995) 1413-1419.

Savy Y., Évolution de la variabilité génétique en sélection naturelle en relation avec le régime de reproduction : étude agronomique de trois pools géniques de blé tendre, étude théorique par simulations informatiques, Rapport de DEA, Institut national agronomique Paris-Grignon, Paris, 1991.

Schoen D., Brown A., Intraspecific variation in population gene diversity and effective population size correlates with the mating system in plants, Proc. Natl. Acad. Sci. USA 88 (1991) 4494-4497. 
Simmonds N.W., Variability in crop plants, its use and conservation, Biol. Rev. 37 (1962) 442-465.

Thomas G., Rousset M., Pichon M., Trottet M., Doussinault G., Picard E., Méthodologie de l'amélioration du blé tendre ( $T$. aestivum L.). I. Création par croisements et analyse d'une population artificielle à 16 parents, base de cette étude méthodologique, Agronomie 11 (1991) 359-368.

Tsegaye S., Estimation of outcrossing rate in landraces of tetraploid wheat (Triticum turgidum L.), Plant Breeding 115 (1996) 195-197.

Weir B.S., Genetic Data Analysis, Sinauer Associates, Inc., Sunderland, MA, 1990. 